\title{
Stabilization of iron-arsenic deposits by encapsulation with montmorillonite inorganic gels
}

\author{
Jingmin Yan $^{1,2}$, Yongliang Wang ${ }^{1,3}$, Yanhua Wang, ${ }^{1,2}$ Xiang Liu ${ }^{1,2}$, Shufeng $\mathrm{Ye}^{1,3^{\dagger}}$ \\ ${ }^{1}$ State Key Laboratory of Multiphase Complex Systems, Institute of Process Engineering, Chinese Academy of Sciences, Beijing 100190, China \\ ${ }^{2}$ School of Chemistry and Chemical Engineering of University of Chinese Academy of Sciences, Beijing 100049, China \\ ${ }^{3}$ Innovation Academy for Green Manufacture, Chinese Academy of Sciences, Beijing 100190, China
}

\begin{abstract}
Encapsulation is recognized as an effective technique for enhancing the stability of hazardous waste by coating it with an inert material. In this work, an eco-friendly montmorillonite (Mt) inorganic gel with the characteristics of high viscosity, adsorption and easy preparation was developed and coated on the surface of iron-arsenic deposits (IAD) to restrain the release of arsenic (As). The encapsulation system investigated involves $\mathrm{Mt} / \mathrm{IAD}$ mass ratio and aging temperature of the coated iron-arsenic deposits (C-IAD). The C-IAD was characterized by XRF, XRD, SEM-EDS, TEM, FTIR and BET. The results revealed that the IAD was completely encapsulated by the montmorillonite inorganic gel. From the experiment of stability, when IAD was coated with montmorillonite inorganic gel $(\mathrm{Mt} / \mathrm{IAD}$ mass ratio 0.75$)$ and aged at $25^{\circ} \mathrm{C}$, As release decreased from $3.15 \mathrm{mg} / \mathrm{L}$ to $0.64 \mathrm{mg} / \mathrm{L}$ at pH 5 after $24 \mathrm{~h}$, and then dropped to $0.11 \mathrm{mg} / \mathrm{L}$ after $7 \mathrm{~d}$. Furthermore, the results indicated that the IAD encapsulated with montmorillonite inorganic gel was effective in suppressing the release of As under both weakly acidic and alkaline conditions.
\end{abstract}

Keywords: Arsenic, Encapsulation, Gel, Ion-exchange, Montmorillonite, Stabilization

\section{Introduction}

Arsenic (As), a nonmetallic element, is widely distributed in nature, and trace amounts of arsenic can be detected in soil, water, minerals and plants, as well as in normal human tissues [1]. Last century, As and its compounds are mainly used in alloy smelting, pesticide medicine, pigment and other industries [2]. At present, As and its compounds are restricted to some areas such as cosmetics industry because of their highly toxic and potent human carcinogen $[1,3]$. Therefore, arsenic-containing residue and effluent must be treated and stored in appropriate ways [4]. As is difficult to control in solution, hence it is usually stored in the crystal structures of secondary arsenic minerals such as iron arsenate $\left(\mathrm{FeAsO}_{4} \cdot 12 \mathrm{H}_{2} \mathrm{O}\right)$, iron ( $\mathrm{Fe}$ ) sulphoarsenates and sulphoarsenites, $\mathrm{Ca}, \mathrm{Mg}$ and $\mathrm{Ca}-\mathrm{Mg}$ arsenates, and arsenic sulfide $\left(\mathrm{As}_{2} \mathrm{~S}_{3}\right)$ [4]. Among them, crystalline ferric arsenate (scorodite) has been proposed as an effective storage material due to its low As release (typically less than $1 \mathrm{ppm}$ As at $\mathrm{pH} \mathrm{5)}$ and its high As content (25-30 wt\%) [5]. However, the synthesis of scorodite requires high temperatures and high-pressure conditions which would be an economic burden to most factories. Normally, an alternative amorphous ferric arsenate was produced under ambient-pressure conditions which reduce the release of As by increasing the molar ratio of $\mathrm{Fe} / \mathrm{As}[6,7]$. Both scorodite and amorphous ferric arsenate are stable only at $\mathrm{pH} 4$ to 7 under aerobic conditions [8, 9], and the carbonation of containing ferric may occur over a long period of time [10]. Therefore, it is beneficial to explore effective methods for enhancing the stability of iron-arsenic compounds.

Encapsulation is the process of coating hazardous waste containing heavy metals/metalloids (such as As) with inert substances to prevent their dissolution [11]. Many studies [12-14] have used encapsulation to improve the stability of solid wastes containing As. Jing et al. [12] utilized the cement as encapsulants for high As content sludge, and the results confirmed that the formation of calcium arsenate can increase the stability of cement-treated sludge. However, calcium arsenate will react with carbon dioxide in the air to consume calcium and reduce the stabilizing effect of cement on sludge. Randall [13] also showed that Portland cement
This is an Open Access article distributed under the terms of the Creative Commons Attribution Non-Commercial License (http://creativecommons.org/licenses/by-nc/3.0/) which permits unrestricted non-commercial use, distribution, and reproduction in any medium, provided the original work is properly cited.

Copyright (C) 2022 Korean Society of Environmental Engineers
Received December 02, 2020 Accepted January 18, 2021

${ }^{\dagger}$ Corresponding author

E-mail: sfye@ipe.ac.cn

Tel: +13911828468 Fax: +86-10-62588029

ORCID: 0000-0002-1046-586X 
with ferrous sulfate and lime could reduce the release of As from arsenic-containing materials, and found that the ligand substitution of $\mathrm{OH}^{-}$and As species will prevent the resorption of As. But both Terra-Bond $^{\mathrm{TM}}$ and PFL treated samples released significantly more mass of As at higher $\mathrm{pH}$ (e.g. $\mathrm{pH}=12$ ). Ke et al. [14] founded that the crystalline polyferric sulfate coating layer can effectively inhibit the release of As from scorodite particles in both weakly acidic and alkaline solutions under both oxic and anoxic conditions. The stabilizing effects of crystalline polyferric sulfate on scorodite are mainly due to the suppression of ion exchange between $\mathrm{PO}_{4}{ }^{3-}$ and $\mathrm{AsO}_{4}{ }^{3-}$ and the adsorption of As by crystalline polyferric sulfate itself. However, encapsulation conditions of this method are relatively harsh, which must be carried out at $90^{\circ} \mathrm{C}$ and $1.5 \mathrm{pH}$. These studies indicate that encapsulation materials present as porous structure consisting of flakes may restrain the release of As from arsenic-containing waste.

The purpose of this paper is to develop a material and method that can control the coating thickness without reducing the stability of arsenic-containing waste, so as to improve the fixation rate of As and reduce the total amount of waste residue. Montmorillonite inorganic gel was selected as encapsulating material because of its three-dimensional network structure and excellent cation exchange performance, which may be effective to encapsulate arsenic-containing wastes and restrain the release of anions such as $\mathrm{AsO}_{4}{ }^{3-}$ and $\mathrm{AsO}_{2}{ }^{-}$. Specifically this paper will investigate the process of montmorillonite inorganic gel production, coating and aging, as well as the stability of encapsulated iron-arsenic deposits under different $\mathrm{pH}$ conditions.

\section{Material and Methods}

\subsection{Materials}

In this study, the water containing As was obtained from the leaching solution of pyrite cinder using $18 \%$ sulphuric acid. The acid leaching was carried out in a $3 \mathrm{~L}$ glass beaker at $85^{\circ} \mathrm{C}$. The pulp was filtered to separation of solid-liquid after $4 \mathrm{~h}$. The Fe and As contents in the filtrate were determined by inductively coupled plasma-atomic emission spectrometry (ICP-OES, Optima 8000). According to the testing results of ICP-OES, the Fe/As molar ratio was approximately 4.5:1 and the As containing in the solution was $2,260 \mathrm{mg} / \mathrm{L}$, and the solution $\mathrm{pH}$ was 0.12 .

Montmorillonite was provided by Beijing Innochem (A77948-500G; CAS:1318-93-0). In addition, iron power, hydrogen peroxide, sodium hydroxide, anhydrous sodium carbonate and calcium oxide were taken from Sinopharm Chemical Reagent Company. All the chemical reagents were analytical grade. Deionized water produced by a water system (Barnsted, Nanopure Ultrapure Water System, specific conductance $<0.057 \mu \mathrm{S} / \mathrm{cm}$ ) was used for all experiments.

\subsection{Preparation of Iron-Arsenic Deposits}

The $\mathrm{pH}$ of the iron-arsenic effluent was adjusted to $0.8-1.0$ by adding $20 \mathrm{wt} \% \mathrm{NaOH}$. Then added excessive reducing iron powder (1.5 times of the theoretical amount) to reduce $\mathrm{Fe}^{\mathrm{III}}$ to $\mathrm{Fe}^{\mathrm{II}}$. The treated effluent was stirred for $6 \mathrm{~h}$ at $50^{\circ} \mathrm{C}$ and filtered to remove the excess iron powder. Then the filtrate was added $20 \mathrm{wt} \% \mathrm{NaOH}$ solution to maintain $\mathrm{pH}$ in the range of 5.0-5.5 when a certain amount of 30 wt\% hydrogen peroxide $\left(\mathrm{H}_{2} \mathrm{O}_{2} / \mathrm{As}\right.$ molar ratio of 2.0) was dripped into the solution. After stirring for $2 \mathrm{~h}$ at room temperature $\left(25^{\circ} \mathrm{C}\right)$, the solution was separated and the residue was washed with deionized water (10 times of the solution) to remove impurities such as $\mathrm{Na}^{+}$and $\mathrm{Ca}^{2+}$. The residue was dried at $100^{\circ} \mathrm{C}$ and subsequently used for encapsulation with montmorillonite inorganic gel.

\subsection{Production of Montmorillonite Inorganic Gel}

Montmorillonite inorganic gel was prepared by the sodium modification and gelatinization of calcium-based montmorillonite. Taken certain quality montmorillonite and added deionized water to prepare $5 \%$ pulp, ultrasonic crush in an ultrasound washer at $25^{\circ} \mathrm{C}$ for $20 \mathrm{~min}$. Then sodium carbonate with $8 \%$ of the mass of montmorillonite was added as the sodium reagent and the pulp was magnetically stirred at $25^{\circ} \mathrm{C}$ for about $20 \mathrm{~min}$. Subsequently, $4 \%$ calcium oxide was added as the gel agent and a viscous gel formed after $15 \mathrm{~min}$ [15]. During the production of montmorillonite inorganic gel, the stirring rate was kept at $100 \mathrm{r} / \mathrm{min}$.

\subsection{Ageing of Iron-Arsenic Deposits with Montmorillonite Inorganic Gel}

The synthetic IAD and montmorillonite inorganic gel were thoroughly blended together and aged under various conditions, including $\mathrm{Mt} / \mathrm{IAD}$ mass ratio $(0,0.1,0.25,0.5,0.75,1,1.25$ and 1.5$)$ in the blended product and aging temperatures $(25,50,75,100$, 125,150 and $175^{\circ} \mathrm{C}$ ). The aged gel-coated products were ground using a pestle and mortar before sample testing.

\subsection{Stability Testing}

The aged gel-coated products were placed in a tube with a cock and used acetate buffering solution to evaluate their long-term stability. Stability testing was done under different conditions $(\mathrm{pH}$ at $3,5,7,9$ and 11) in order to better assess the efficacy of the encapsulation capability of the montmorillonite inorganic gel. Acetate buffering solution of $\mathrm{pH} 3$ was obtained by dissolving 5.7 $\mathrm{mL}$ of glacial $\mathrm{CH}_{3} \mathrm{CH}_{2} \mathrm{OOH}$ with reagent water to a volume of 1 L. Other buffers of different $\mathrm{pH}(\mathrm{pH}$ at 5, 7, 9 and 11) were obtained as follows: $1 \mathrm{M} \mathrm{NaOH}$ solution was added dropwise to a buffer of $\mathrm{pH} 3$ until the predetermined $\mathrm{pH}$ value was reached. In order to sample multiple times during the long-term stability test, the liquid to solid ratio (L/S) was kept at 40 for all tests [11]. The tube was placed and fixed on a horizontal vibrating device with vibrating frequency at 110 times/min under room temperature $\left(22^{\circ} \mathrm{C}\right)$. Samples were taken on a regular basis with 5 $\mathrm{mL}$ syringes and then filtered using $0.2 \mu \mathrm{m}$ membranes, and the filtered liquor was diluted with a $4 \%$ nitric acid solution to prepare for analysis of Fe and As concentrations using ICP.

\subsection{Analysis and Characterization}

The contents of Fe and As in the solid were obtained by dissolving the solid with $\mathrm{HCl}$ and $\mathrm{HNO}_{3}$ and then using ICP-OES to measure the content of elements in the solution as described in our previous paper [16]. The $\mathrm{pH}$ value was detected by $\mathrm{pH}$ meter (pHs-3E, Leici, 
China). The chemical analysis for starting materials was carried out with WD XRF fluorescence spectrometer Axios mAX $4 \mathrm{~kW}$ by PANalitycal company, equipped with Rh source. XRD measurements were carried on a Philips X'Pert Pro diffractometer equipped with $\mathrm{Cu} \mathrm{K} \alpha$ radiation $(\mathrm{l}=0.15418 \mathrm{~nm})$. The total metal ions concentrations in the solution were measured by inductively coupled plasma-atomic emission spectrometry (ICP-OES, Optima 8000). The surface morphology and microstructure of the samples were characterized by the high-resolution field emission transmission electron microscope (TEM, JEM-2100F) and the scanning electron microscope (SEM, model 6700F, Tokyo, Japan) with energy dispersive spectrometer (EDS). Elemental mapping of particle cross-sections was achieved by mounting particles in cold-setting epoxy resin, polishing the samples and coating with a gold/palladium layer before obtaining X-ray maps with a Hitachi S-3000N variable pressure scanning electron microscope (VP-SEM). Teller (BET) specific surface area and pore structures were measured by $\mathrm{N}_{2}$ adsorption-desorption isotherms at $77 \mathrm{~K}$ with ASAP 2020 apparatus (Micromertics, USA). The infrared absorption test was conducted to indicate the structures of the precipitates using Fourier transform infrared spectrometer (FTIR, Excalibur 3100).

\section{Results and Discussion}

\subsection{The Chemical Composition Analysis of Raw Materials}

The chemical composition of the montmorillonite, montmorillonite inorganic gel, IAD and C-IAD (Mt/IAD 0.75; aged at $25^{\circ} \mathrm{C}$ ) is presented in Table S1. The chemical analysis showed that montmorillonite and montmorillonite inorganic gel has a high content of $\mathrm{SiO}_{2}$ (over 66 wt\%), the increase of $\mathrm{Na}_{2} \mathrm{O}$ and $\mathrm{CaO}$ in gel is due to the addition of sodium reagent and gel agent in the preparation process of gel. IAD showed the significant presence of $\mathrm{Fe}_{2} \mathrm{O}_{3}$ (34.573 wt\%), the presence of $\mathrm{SO}_{3}$ (28.625 wt\%) and $\mathrm{As}_{2} \mathrm{O}_{3}$ (11.182 wt\%) proved that IAD was prepared from acidic arsenic-containing effluent. Moreover, C-IAD exhibited high content of $\mathrm{SiO}_{2}(42.145$ wt\%) and $\mathrm{Fe}_{2} \mathrm{O}_{3}$ (21.483 wt\%), which was the mixture of gel and IAD.

\subsection{The Theoretical Basis of the Formation of Montmorillonite Inorganic Gel}

Montmorillonite is a layered mineral composed of very fine water-containing aluminosilicate with substantial isomorphic substitution, belonging to the monoclinic crystal system. Its crystal structure is a 2:1 layered silicate with each layer composed of one aluminum (magnesium) oxygen octahedral sheet sandwiched between two tetrahedral silicate sheets [17, 18]. Montmorillonite has strong cation exchange performance and water swelling performance, so the high-valent cations in the crystal structure are easily replaced by low-valent large-radius cations [19]. However, As usually exists in the form of two anions $\left(\mathrm{AsO}_{4}{ }^{3-}\right.$ and $\left.\mathrm{AsO}_{2}{ }^{-}\right)$, and will not be affected by the cation exchange performance of montmorillonite. The montmorillonite used in this study was Ca-montmorillonite, which was first modified by adding sodium carbonate into the slurry during the preparation of the gel. When sodium modification, one $\mathrm{Ca}^{2+}$ is usually replaced by two $\mathrm{Na}^{+}$.

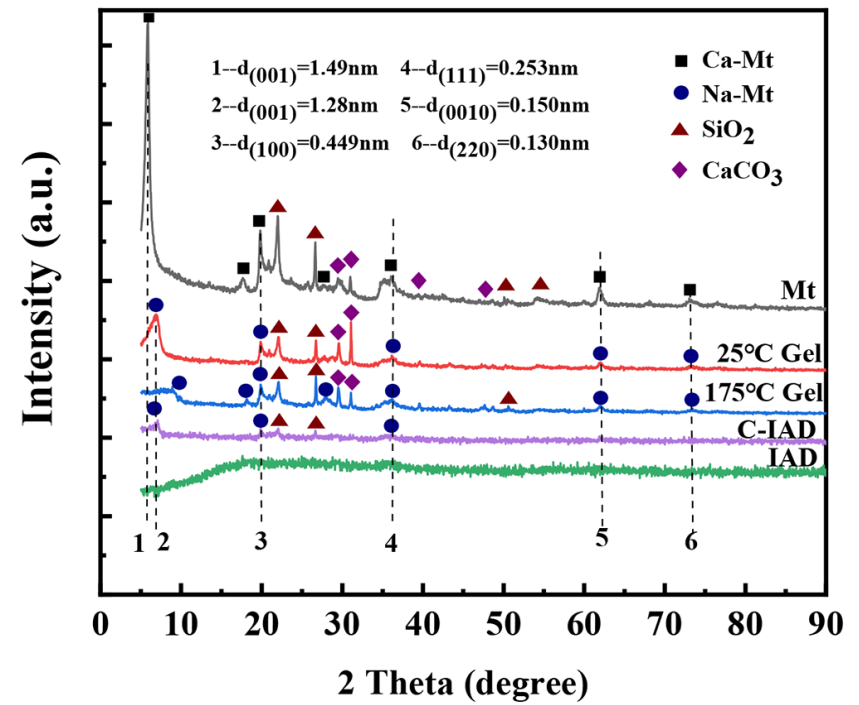

Fig. 1. XRD patterns of the montmorillonite, $I A D$, montmorillonite inorganic gel (aged at $25^{\circ} \mathrm{C}$ and $175^{\circ} \mathrm{C}$ ) and C-IAD (Mt/IAD 0.75; aged at $25^{\circ} \mathrm{C}$ ).

Na-montmorillonite has a higher Zeta potential, the particles are not easy to agglomerate, and the montmorillonite sheets have good dispersibility [20]. After the addition of the gelling agent $\mathrm{CaO}$, the end faces of montmorillonite sheets were connected with each other by $\mathrm{Ca}^{2+}$ under the action of static electricity to form an inorganic gel with a three-dimensional grid structure [21].

Fig. 1 shows the XRD patterns of the montmorillonite, IAD, montmorillonite inorganic gel (aged at $25^{\circ} \mathrm{C}$ and $175^{\circ} \mathrm{C}$ ) and C-IAD $\left(\mathrm{Mt} / \mathrm{IAD} 0.75\right.$; aged at $25^{\circ} \mathrm{C}$ ). And the standard peaks of the corresponding reference materials are shown in Fig. S1. XRD pattern of montmorillonite exhibits intense diffraction peaks at angles $(2 \theta)$ of $5.9,19.8,20.8,26.6,29.4$ and $31.5^{\circ}$, indicating that the main mineral phases of montmorillonite are calcium montmorillonite (Ca-Mt), silica $\left(\mathrm{SiO}_{2}\right)$ and calcium carbonate $\left(\mathrm{CaCO}_{3}\right)$. After the preparation of the gel with montmorillonite, the peaks of the Ca-Mt decrease significantly and shifted to the right, the peak type became flat and broad. Meanwhile, according to Bragg's equation: $\lambda=2 \mathrm{~d} \sin \theta$, the $\mathrm{d}_{(001)}$ decreased from $1.49 \mathrm{~nm}$ to $1.28 \mathrm{~nm}$, indicating that there is residual Na-Mt in the gel.

\subsection{Characterization of Gel Coating}

Fig. 2(a) presents the contents of Fe and As in the IAD and C-IAD with different $\mathrm{Mt} / \mathrm{IAD}$ mass ratios aged at $100^{\circ} \mathrm{C}$. The results demonstrate that Fe content is decreased from 22.18 to $10.77 \%$ and As content is decreased from 7.95 to $3.46 \%$ as the Mt/LAD mass ratio increased from 0 to 1.5. X-ray diffraction patterns of the C-IAD (aged at $100^{\circ} \mathrm{C}$ ) with different $\mathrm{Mt} / \mathrm{IAD}$ mass ratios are shown in Fig. 2(b). There are no characteristic peaks in IAD (Mt/IAD mass ratio is 0), indicating that they are poorly-crystalline [7]. Only one broad peak is observed in the range of $2 \theta=10-30^{\circ}$. This broad peak disappeared obviously even at the very low Mt/IAD mass ratio of 0.1 indicating that the montmorillonite inorganic gel successfully covered the surface of the precipitate. The diffraction peaks 

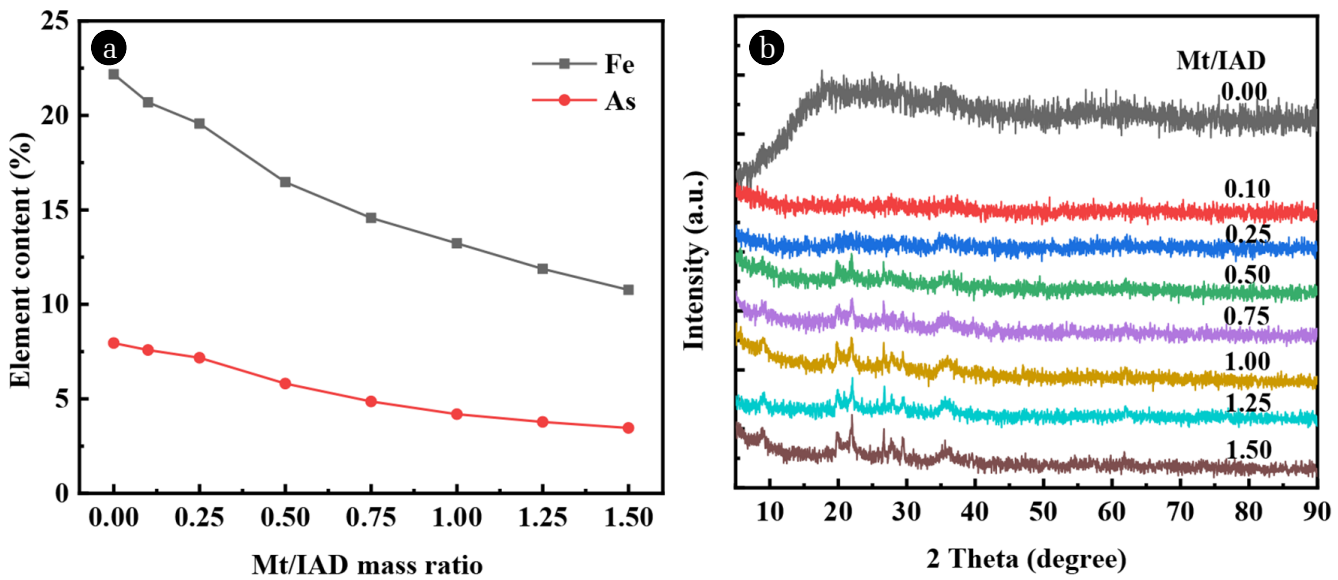

Fig. 2. Element content and XRD patterns of C-IAD (aged at $100^{\circ} \mathrm{C}$ ) with different $\mathrm{Mt} / \mathrm{IAD}$ mass ratios: (a) Element content of Fe and $\mathrm{As}$; (b) XRD patterns.

of the montmorillonite are gradually discernible with the increase of montmorillonite dosage, and we conclude that the peaks in the coated products correspond to the two mineral phases of IAD and montmorillonite inorganic gel.

SEM images of the IAD and C-IAD (aged at $25^{\circ} \mathrm{C}$ ) under different magnification and the TEM image of the C-IAD (Mt/IAD 0.75; aged at $100^{\circ} \mathrm{C}$ ) are illustrated in Fig. 3. It can be seen that the surface of the uncoated IAD is relatively smooth. As can be seen in Fig. 3(a)-(c), the surface of the coated product is getting rougher as the $\mathrm{Mt} / \mathrm{IAD}$ mass ratios increase from 0 to 0.75 . As shown in Fig. $3(\mathrm{~b})$, the surface of the coated product (Mt/IAD 0.1) is coated with fine flakes, and the coating is relatively uniform. Fig. 3(c) shows that the flakes accumulate randomly on the solid surface and more irregular porous structures appear when the Mt/IAD mass ratio is 0.75 . The TEM image of Fig. 3(d) presents that the montmorillonite inorganic gel coating is closely bound to IAD and its thickness
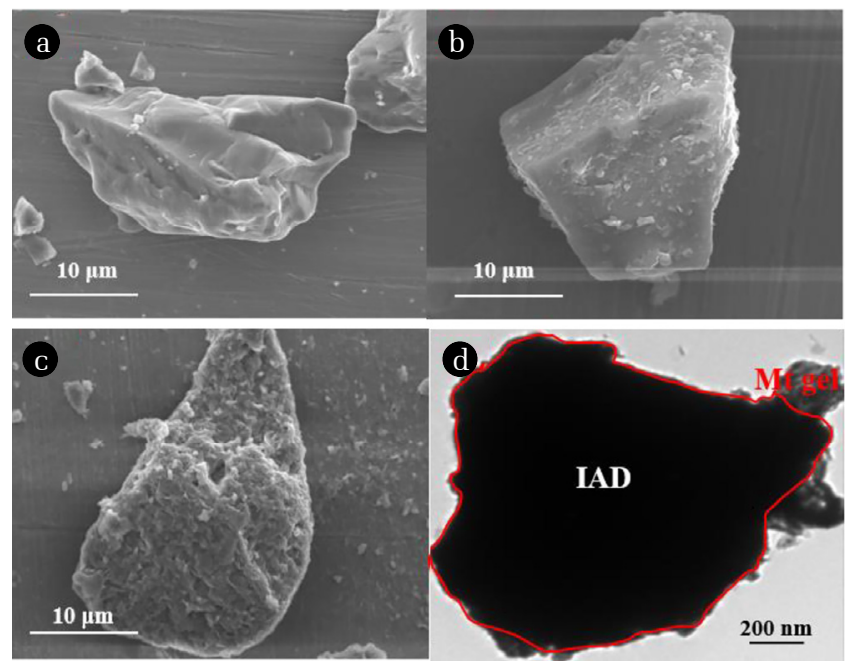

Fig. 3. SEM and TEM images of the IAD and C-IAD: (a) surface structure of IAD; (b) surface structure of C-IAD (Mt/IAD mass ratio is 0.10$)$; (c) surface structure of C-IAD (Mt/IAD mass ratio is 0.75$)$; (d) TEM image of C-IAD (Mt/IAD mass ratio is 0.75$)$. is uneven. The special morphology indicates that the increase of montmorillonite dosage may produce a certain adsorption capacity $[22,23]$.

Fig. 4 exhibits SEM and backscattered electron (BSE) images of the cross section of the coated products (Mt/IAD 0.75; aged at $25^{\circ} \mathrm{C}$ ) along with the associated EDS mapping. Fe, Si and As elemental X-ray maps of Fig. 4(b) confirm that the core material of the coated products is IAD and the montmorillonite inorganic gel has formed a mineralized matrix around the IAD. This coating layer is not uniform. As we can see in Fig. 4(c), BSE image shows that region $B$ is dark in color and obviously different from other regions, indicating that the region $\mathrm{B}$ is an independent phase different from regions $\mathrm{A}$ and $\mathrm{C}$. And SEM-EDX radial compositional analysis results at line $\mathrm{L}$ in Fig. $4(\mathrm{~d})$ show that the $\mathrm{Si} / \mathrm{Fe}$ ratio is obviously different in the $\mathrm{A}, \mathrm{B}$, and $\mathrm{C}$ regions, which is related to their phase. Combining Fig. 4(c) and Fig. 4(d), we speculate that through the coating of montmorillonite inorganic gel, it has
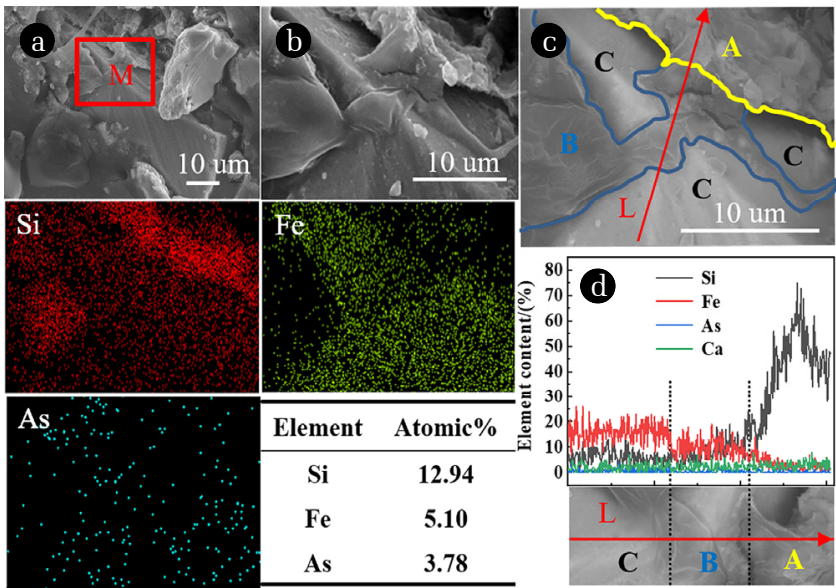

Fig. 4. SEM image, backscattered electron (BSE) image and elemental X-ray maps of the cross section of C-IAD (Mt/IAD 0.75; aged at $25^{\circ} \mathrm{C}$ ): (a) SEM image; (b) SEM image of $M$ area in (a); (c) Backscattered electron (BSE) image of (b); (d) SEM-EDX radial compositional analysis at line $\mathrm{L}$ in (c). 
a high probability of forming a tightly bound intermediate layer between the gel and IAD. Obviously, it can be seen that region $A$ is montmorillonite inorganic gel, region $C$ is $\mathrm{IAD}$, and region $\mathrm{B}$ may be the ferric silicate intermediate layer between IAD and gel [11].

Fourier transform infrared (FTIR) spectrum of montmorillonite, $\mathrm{IAD}$, montmorillonite inorganic gel (aged at $25^{\circ} \mathrm{C}$ and $175^{\circ} \mathrm{C}$ ) and C-IAD (Mt/IAD 0.75; aged at $25^{\circ} \mathrm{C}$ ) are shown in Fig. 5. At $400-800$ $\mathrm{cm}^{-1}$, the spectra of IAD shows the bending and stretching vibration peaks of O-As-O and As-O at 432 and $610 \mathrm{~cm}^{-1}$, which are the main differences between IAD and C-IAD [12, 24, 25]. And the bands of O-As-O and As-O are not shown in the spectra of C-IAD because they are masked by the bending stretching vibration peak of Si-O-Si band as well as weak stretching vibration peak of Si-O band, which usually occurs in the range of $400-500 \mathrm{~cm}^{-1}$ and $\sim 660$ $\mathrm{cm}^{-1}[26,27]$. All samples have a complex group of bands at $\sim 1,060$ $\mathrm{cm}^{-1}$ that is attributed to the asymmetric and symmetric stretching vibrations of Si-O bonds $[27,28]$. The increase in the strength

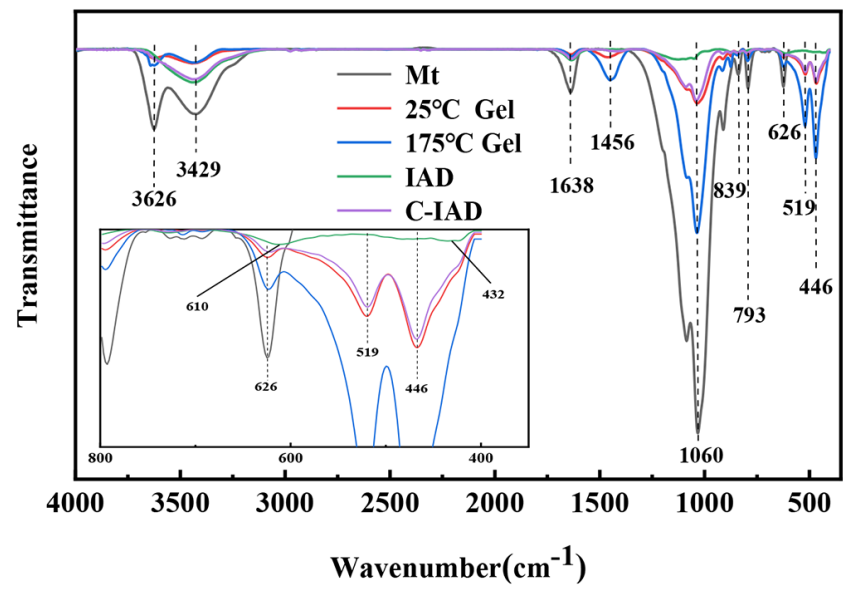

Fig. 5. FT-IR spectra of montmorillonite, $I A D$, montmorillonite inorganic gel (aged at $25^{\circ} \mathrm{C}$ and $175^{\circ} \mathrm{C}$ ) and C-IAD (Mt/IAD 0.75; aged at $\left.25^{\circ} \mathrm{C}\right)$. of this peak indicates the polymerization of silicate. These differences reflect its more extensive polymerization of the silicate due to the encapsulation of montmorillonite inorganic gel. The weak shoulder at $839 \mathrm{~cm}^{-1}$ is attributed to the out-of-plane bending of $\mathrm{CO}_{3}{ }^{2-}$, and the band at $1,456 \mathrm{~cm}^{-1}$ correspond to the asymmetric stretching of $\mathrm{CO}_{3}{ }^{2-}$ [27]. All samples produced essentially identical spectra at 1,638 and $3,429 \mathrm{~cm}^{-1}$, where the peaks are assigned to $\mathrm{OH}^{-}$and $\mathrm{H}_{2} \mathrm{O}$ groups $\left[11,24,27\right.$. The $3,626 \mathrm{~cm}^{-1}$ band in these samples probably corresponding to $\mathrm{CaOH}$ groups [27].

The specific surface and the pore structures of IAD and C-IAD (Mt/IAD 0.75 , aged at $25^{\circ} \mathrm{C}$ ) are obtained by the $\mathrm{N}_{2}$ adsorption-desorption isotherm (see Fig. 6). A hysteresis loop is present in the adsorption isotherm of IAD in Fig. 6(a) indicating the presence of abundant mesopores [29]. Pore size distribution analysis (Fig. 6(b)) shows that both $\mathrm{IAD}$ and $\mathrm{C}-\mathrm{IAD}$ have narrow pore distribution in the range of $10-20 \AA$, and the average pore radius of the IAD and the C-IAD are $51.4 \AA$ and $38.4 \AA$, respectively. Correspondingly, the specific surface area of C-IAD $\left(86.902 \mathrm{~m}^{2} \mathrm{~g}^{-1}\right)$ is larger than that of IAD (30.989 $\left.\mathrm{m}^{2} \mathrm{~g}^{-1}\right)$. The noticeable increase in surface area of C-IAD is attributed to the encapsulation of montmorillonite inorganic gel, which has a porous network structure [21, 30, 31]. And C-IAD has a smaller pore radius, which helps to restrain the release of As.

\subsection{Ageing of Montmorillonite Inorganic Gel}

The aging process of C-IAD is essentially the hydration process of the gel. Hydration of the gel system is a complicated process and mainly affected by temperature. The XRD patterns of the montmorillonite inorganic gel aged at $25^{\circ} \mathrm{C}$ and $175^{\circ} \mathrm{C}$ are illustrated in Fig. 1. As can be seen, compared with the $25^{\circ} \mathrm{C}$ gel, the intensity of the XRD spectra of Na-Mt and $\mathrm{CaCO}_{3}$ in $175^{\circ} \mathrm{C}$ gel is reduced, while that of $\mathrm{SiO}_{2}$ is enhanced. The XRD results show that the increase of aging temperature will promote the hydration process and increase the crystallinity of $\mathrm{SiO}_{2}$ [27]. The FTIR spectral bands of the montmorillonite inorganic gel aged at $25^{\circ} \mathrm{C}$ and $175^{\circ} \mathrm{C}$ can be seen in Fig. 5. When the temperature rises from 25 to $175^{\circ} \mathrm{C}$, there is an increase in the intensity of $\mathrm{Si}-\mathrm{O}, \mathrm{Si}-\mathrm{O}-\mathrm{Si}, \mathrm{CO}_{3}{ }^{2-}$ and
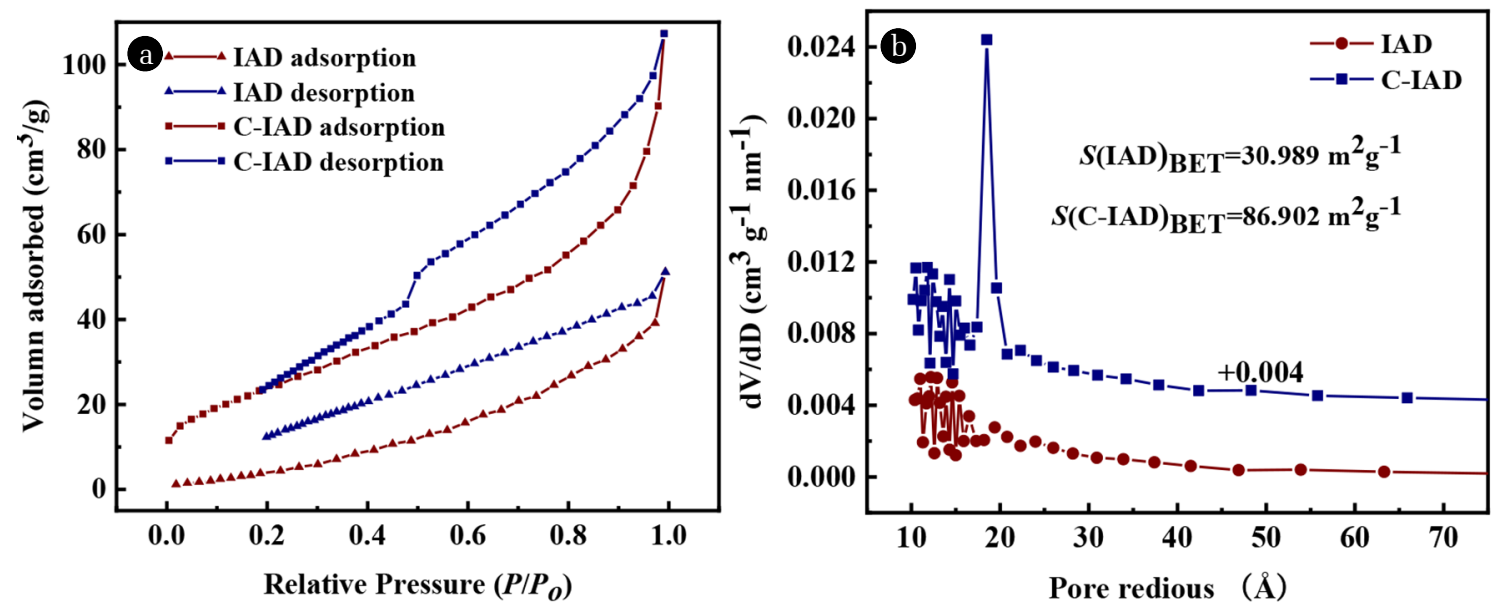

Fig. 6. Nitrogen adsorption - desorption isotherms (a) of IAD and C-IAD $\left(\mathrm{Mt} / \mathrm{IAD} 0.75\right.$; aged at $25^{\circ} \mathrm{C}$ ) and (b) the corresponding pore size distribution curve calculated from the desorption branch of the nitrogen isotherm by the $\mathrm{BJH}$ method. 
$\mathrm{CaOH}$ peaks at 1,060, 446, 519, 839, 1,456 and 3,626 $\mathrm{cm}^{-1}$, and a decrease in the intensity of $\mathrm{H}_{2} \mathrm{O}$ peaks at 1,638 and $3,429 \mathrm{~cm}^{-1}$. These observations indicate that the increase of aging temperature will lose the $\mathrm{OH}^{-}$group and increase the degree of polymerization of the silicate chain [26, 32]. The conclusion is consistent with the results of XRD analysis, where the characteristic peaks strength of $\mathrm{SiO}_{2}$ also increased when the aging temperature increased from $25^{\circ} \mathrm{C}$ to $175^{\circ} \mathrm{C}$ in Fig. 1.

\subsection{Stability Experiments}

\subsubsection{Effect of the Mt/IAD mass ratio}

Fig. 7(a) displays the results of the leaching concentrations of $\mathrm{Fe}$ and As in the filtrate from the leaching toxicity tests at $\mathrm{pH} 5.0$ for $24 \mathrm{~h}$. The pure IAD and the C-IAD with different Mt/IAD mass ratios $(0.1,0.25,0.5,0.75,1,1.25$ and 1.5$)$ are all aged at $25^{\circ} \mathrm{C}$. It can be seen that the leaching concentrations of Fe decrease from 42.9 to $1.611 \mathrm{mg} / \mathrm{L}$ when the ratio of $\mathrm{Mt} / \mathrm{IAD}$ is 0.1 and the Fe release is not detectable when the $\mathrm{Mt} / \mathrm{IAD}$ mass ratio increase to 0.75 . The release of As from uncoated IAD is $3.152 \mathrm{mg} / \mathrm{L}$ at $\mathrm{pH}$ 5.0 after $24 \mathrm{~h}$. For IAD coated with montmorillonite inorganic gel, the As in the leaching solution decreases to $1.723 \mathrm{mg} / \mathrm{L}$ when the $\mathrm{Mt} / \mathrm{IAD}$ mass ratio is 0.1. However, the restrain of As release hardly increases with the further increase of montmorillonite dosage. In Fig. 7(a), it can be clearly seen that there are two inflection points on the As concentration curve, respectively at the Mt/IAD of 0.1 and 0.75. Linear fitting was carried out for line segment ab, bc and $\mathrm{cd}$, and it can be known that the slope was $-14.29,-0.49$ and -0.16 respectively. The change in slope indicates that the effect of montmorillonite inorganic gel on As release hardly increases with the increase of $\mathrm{Mt} / \mathrm{IAD}$ mass ratio after reaching 0.75. Combined with Fig. 2(a), after the Mt/IAD mass ratio reaches 0.75 , the reduction of As leaching toxicity may only be due to the decrease of As content in the coated products. The results showed that montmorillonite inorganic gel could effectively inhibit the leaching of Fe and As, even at the very low $\mathrm{Mt} / \mathrm{IAD}$ mass ratio of 0.1 .

\subsubsection{Effect of the leaching $\mathrm{pH}$}

The C-IAD prepared with 0.75 times the mass ratio of $\mathrm{Mt} / \mathrm{IAD}$, which after aging for $24 \mathrm{~h}$ in the oven at $25^{\circ} \mathrm{C}$ is subjected to stability testing under different $\mathrm{pH}$ conditions $(\mathrm{pH}$ at $3,5,7,9$ and 11) over 7 d. Fig. 7(b) indicates the relationship of As concentration with time under different $\mathrm{pH}$ conditions. As can be seen in Fig. 7(b), the concentration of As decreases with the increase of time under different $\mathrm{pH}$ conditions, indicating that montmorillonite inorganic gel had stable adsorption characteristics. And it can be seen that the C-IAD is more stable in weakly acidic and neutral conditions ( $\mathrm{pH}$ at 5 and 7) and less stable in acidic or alkaline conditions ( $\mathrm{pH}$ at 3, 9 and 11). Fig. 7(b) also shows that the As concentration showed an increasing trend in the first three days at $\mathrm{pH} 9$ and 11. The reason is that the adsorption rate of montmorillonite to arsenic under alkaline condition is slow [33, 34], which is lower than the leaching rate of arsenic in the early stage. The poor stability of C-IAD under acidic conditions $(\mathrm{pH}$ $=3$ ) probably owe to the fact that the montmorillonite gel itself is an alkaline material and acid conditions will destroy its network structure. Although the stability of C-IAD is lower in acidic environment (As release $2.47 \mathrm{mg} / \mathrm{L}$ after $24 \mathrm{~h}$ ), it is still higher than that of uncoated IAD in weakly acidic condition (As release $3.15 \mathrm{mg} / \mathrm{L}$ after $24 \mathrm{~h}$ in Fig. 7(a)). Therefore, it can be concluded that the montmorillonite inorganic gel coating could restrain the release of As from IAD in both weakly acidic and alkaline conditions.

\subsubsection{Effect of the aging temperature}

Fig. 8(a) illustrates the results of As release from IAD and C-IAD (Mt/IAD mass ratio 0.75) under the weakly acidic conditions for $7 \mathrm{~d}$ using an acetate buffering solution of $\mathrm{pH}$ 3. It can be seen that the As release is indeed reduced when IAD are coated with montmorillonite inorganic gel. After $7 \mathrm{~d}$ of leaching test, the As release from C-IAD (aged at $25^{\circ} \mathrm{C}$ ) decrease from 0.64 to $0.11 \mathrm{mg} / \mathrm{L}$, but the As release from uncoated IAD increase from 3.15 to 3.49 $\mathrm{mg} / \mathrm{L}$. The results show that montmorillonite inorganic gel could not only restrain the release of As in IAD, but also adsorb As in solution. Fig. 8(b) shows the relationship between As concentration in the leaching solution $(\mathrm{pH}=5.0)$ and aging temperature after $24 \mathrm{~h}$. As can be seen in Fig. 8(b), the As concentration first increases and then decreases as the temperature increases. And
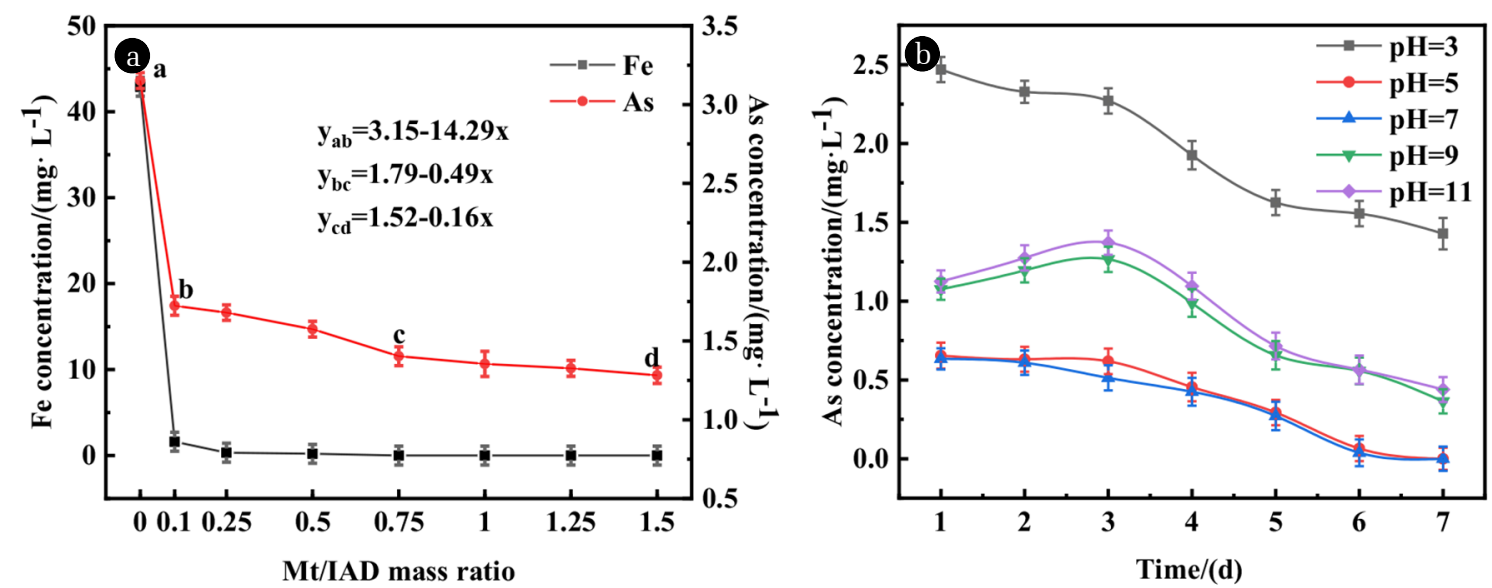

Fig. 7. Stability experiments: (a) Fe and As release from IAD and C-IAD (aged at $25^{\circ} \mathrm{C}$ ) after $24 \mathrm{~h}$ of equilibration at pH 5.0; (b) As release from C-IAD $\left(\mathrm{Mt} / \mathrm{IAD}=0.75\right.$, aged at $\left.25^{\circ} \mathrm{C}\right)$ under different $\mathrm{pH}$ conditions. 

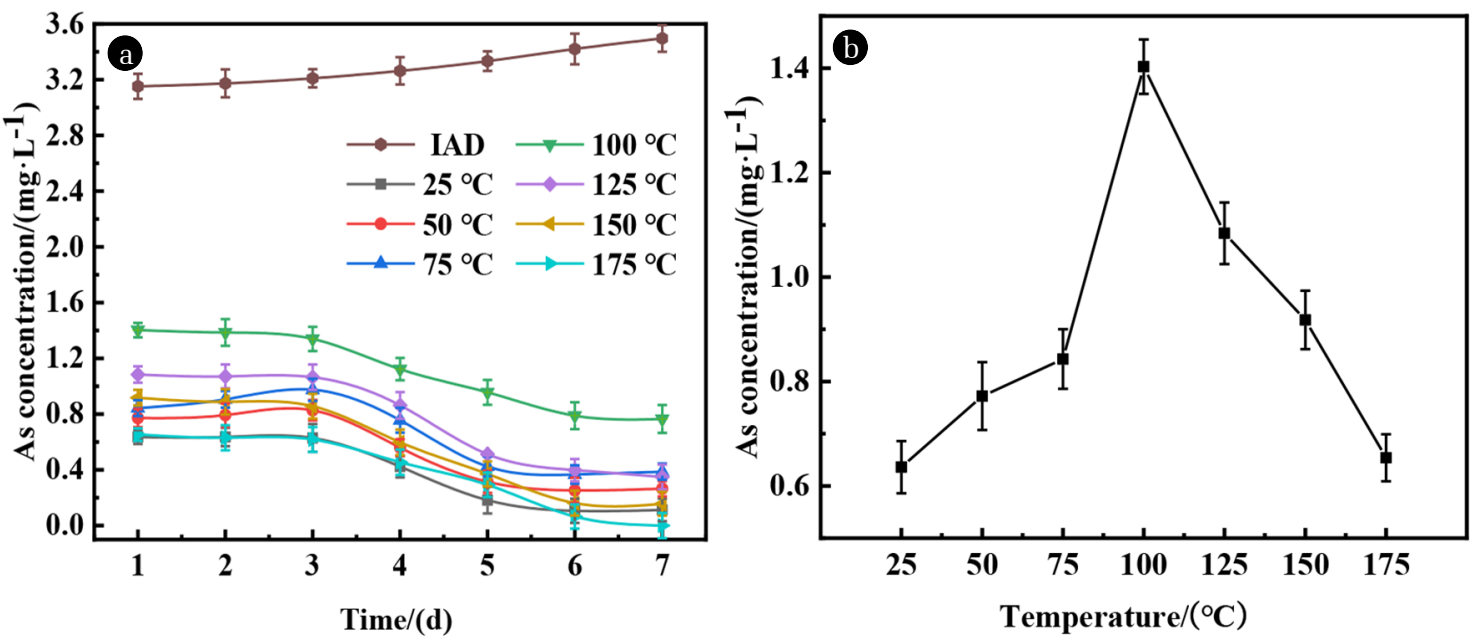

Fig. 8. As release from IAD and C-IAD $(\mathrm{Mt} / \mathrm{IAD}=0.75)$ under different aging temperatures: (a) after $7 \mathrm{~d}$ of equilibration at $\mathrm{pH} 5.0$ and (b) after $24 \mathrm{~h}$ of equilibration at $\mathrm{pH}$ 5.0.

aged sample has the highest initial As release $(1.403 \mathrm{mg} / \mathrm{L})$ at $100^{\circ} \mathrm{C}$. Combined with the analysis of the aging of montmorillonite inorganic gel, we can know that the release of As increases as the aging temperature increases from $25^{\circ} \mathrm{C}$ to $100^{\circ} \mathrm{C}$. It may be caused by the reduction of water molecules and $\mathrm{OH}^{-}$groups in the gel, and further caused the collapse of the silicate layer. After the temperature exceeds $100^{\circ} \mathrm{C}$, the layer structure collapses to a point and the gel structure becomes denser, increasing its inhibition on As release. The results are consistent with Xiandong Cong, who said that oven dry $\left(110^{\circ} \mathrm{C}\right)$ of gel not only has the collapse of the layer structure, but also changed in the polymerization of silicate chains [35].

In summary, when IAD was coated with montmorillonite inorganic gel (Mt/IAD mass ratio 0.75$)$ and aged at $25^{\circ} \mathrm{C}$, As release decreased from $3.15 \mathrm{mg} / \mathrm{L}$ to $0.11 \mathrm{mg} / \mathrm{L}$ at $\mathrm{pH} 5$ after $7 \mathrm{~d}$. The inhibition rate of inorganic montmorillonite gel to arsenic release was $96.51 \%$, which was higher than that of aluminum phosphate gel (90\%) [36] and aluminum chloride gel (31.82\%) [24]. The excellent encapsulation ability of montmorillonite inorganic gel may be attributed to the combination of the ferric silicate intermediate layer formed by the reaction of the montmorillonite gel with IAD and the adsorption capacity of the montmorillonite itself.

\subsection{Mechanism Analysis}

Through the stability test of C-IAD prepared and aged under different conditions, it can be seen that the use of montmorillonite inorganic gel has the ability to inhibit the release of As and adsorb As in solution. The possible inhibitory mechanism of montmorillonite inorganic gel on the As release is shown in Fig. S2. The silicate flakes in the montmorillonite inorganic gel first adhered to the IAD uniformly as a single layer and then piled up in a grid to form a porous structure as the amount of montmorillonite increased. An intermediate layer of iron silicate may have formed between $\mathrm{IAD}$ and the montmorillonite inorganic gel. The intermediate layer may have been formed by the silicate reacting with $\mathrm{Fe}^{\mathrm{III}}$ on the surface of IAD, since the stability constant of the iron-silicate complex is much higher than the complexes that form between arsenate and $\mathrm{Fe}^{\mathrm{III}}$ (at least 7 orders of magnitude difference) [11]. This behavior can be explained by an "ion exchange"-type process between $\mathrm{SiO}_{3}{ }^{2-}$ and $\mathrm{AsO}_{4}^{3-}$ according to reaction (1):

$$
\begin{aligned}
& 2 \mathrm{FeAsO}_{4} \cdot x \mathrm{H}_{2} \mathrm{O}+3 \mathrm{SiO}_{3}{ }^{2-} \rightarrow \\
& \mathrm{Fe}_{2}\left(\mathrm{SiO}_{3}\right)_{3} \cdot x \mathrm{H}_{2} \mathrm{O}+2 \mathrm{AsO}_{4}{ }^{3-}
\end{aligned}
$$

Montmorillonite itself has a certain adsorption capacity [37, 38], so As released during the ion exchange reaction and As in the aqueous solution may be adsorbed in the gel network. This can be demonstrated by our results in Fig. 4(c)-(d), where the gels in region A also contain small amounts of As. And the adsorption of arsenic on montmorillonite is mainly through the attraction of arsenic by the metal hydroxyl groups (such as $\mathrm{Al}-\mathrm{OH}, \mathrm{Mg}-\mathrm{OH}$ and $\mathrm{Fe}-\mathrm{OH}$ ) on the surface and inside of montmorillonite to form outer sphere complex and inner sphere complex [39, 40].

\section{Conclusions}

Montmorillonite inorganic gels were used to stabilize the hazardous arsenical material. The major findings in the current study include: (1) The characterization results showed that the IAD was encapsulated completely by montmorillonite inorganic gel on its surface. Optimum encapsulating conditions are the $\mathrm{Mt} / \mathrm{IAD}$ mass ratio of 0.75 and the aging temperature of $25^{\circ} \mathrm{C}$. (2) The stability tests presented that the coated of IAD with montmorillonite inorganic gel appears to be effective in restraining the release of As under both weakly acidic and alkaline solutions (pH 3 to 11). Under optimal encapsulating conditions, after equilibrating in a buffer solution at $\mathrm{pH} 5$ for $24 \mathrm{~h}$, the As released from uncoated IAD and C-IAD was $3.15 \mathrm{mg} / \mathrm{L}$ and $0.64 \mathrm{mg} / \mathrm{L}$, respectively. What's more, the As released from uncoated IAD increased to $3.50 \mathrm{mg} / \mathrm{L}$ and the As released from C-IAD decreased to $0.11 \mathrm{mg} / \mathrm{L}$ after $7 \mathrm{~d}$. (3) Arsenic is immobilized in the montmorillonite inorganic gel through a combination of encapsulation and adsorption. Through encapsulation, a resistant iron-silicate layer may have formed between the 
$\mathrm{IAD}$ and the montmorillonite inorganic gel by an "ion exchange" reaction between $\mathrm{SiO}_{3}{ }^{2-}$ and $\mathrm{AsO}_{4}{ }^{3-}$. Through adsorption, As released by ion exchange is adsorbed in the porous network structure of montmorillonite inorganic gel.

\section{Acknowledgement}

This work was financially supported by the Innovation Academy for Green Manufacture, Chinese Academy of Sciences (No. IAGM-2019-A05) and the National Key Research and Development Program (No. 2019YFC1904204).

\section{Author Contributions}

J.Y. (Master student) conducted all the experiments and wrote the articles. Y.W. (Associate professor) got funding and modified the article. Y.W. (Master student) conducted supplementary experiments and reviewed the data. X.L. (Ph.D. student) assisted in some of the experiments. S.Y. (Professor) conducted experimental supervision, paper review and financial support.

\section{Reference}

1. Choong TSY, Chuah TG, Robiah Y, et al. Arsenic toxicity, health hazards and removal techniques from water: an overview. Desalination 2007;217(1-3):139-166.

2. Drahota P, Filippi M. Secondary arsenic minerals in the environment: A review. Environ. Int. 2009;35(8):1243-1255.

3. Chaudhuri A N, Basu S, Chattopadhyay S, et al. Effect of high arsenic content in drinking water on rat brain. Indian J. Biochem. Biophys. 1999;36(1):51-54.

4. Kitamura Y, Okawa H, Sugawara K. Synthesis of large scorodite particles using short period time sonication to enhance agglomeration of precursor. Jpn. J. Appl. Phys. 2015;54(7):1347-4065.

5. Langmuir D, Mahoney J, Rowson J. Solubility products of amorphous ferric arsenate and crystalline scorodite $\left(\mathrm{FeAsO}_{4} \cdot 2 \mathrm{H}_{2} \mathrm{O}\right)$ and their application to arsenic behavior in buried mine tailings. Geochim.Cosmochim. Acta. 2006;70(12):2942-2956.

6. Filippou D, Demopoulos GP. Arsenic immobilization by controlled scorodite precipitation. JOM. 1997;49(12):52-55.

7. Wang Y, Lv C, Xiao L, et al. Arsenic removal from alkaline leaching solution using Fe (III) precipitation. Environ. Technol. 2019;40(13):1714-1720.

8. Rochette EA, Li GC, Fendorf SE. Stability of arsenate minerals in soil under biotically generated reducing conditions. Soil Sci. Soc. Am. J. 1998;62(6):1530-1537.

9. Harvey MC, Schreiber ME, Rimstidt JD, et al. Scorodite dissolution kinetics: Implications for arsenic release. Environ. Sci. Technol. 2006;40(21):6709-6714.

10. Robins RG. Solubility and stability of scorodite, $\mathrm{FeSO}_{4}$. ${ }_{2} \mathrm{H}_{2} \mathrm{O}$-Discussion. Am. Mineral. 1987;72(7-8):842-844.

11. Adelman JG, Elouatik S, Demopoulos GP. Investigation of sodium silicate-derived gels as encapsulants for hazardous materials--the case of scorodite. J. Hazard. Mater. 2015;292:108-117.
12. Jing CY, Korfiatis GP, Meng XG. Immobilization mechanisms of arsenate in iron hydroxide sludge stabilized with cement. Environ. Sci. Technol. 2003;37(21):5050-5056.

13. Randall PM. Arsenic encapsulation using Portland cement with ferrous sulfate/lime and Terra-Bond (TM) technologies Microcharacterization and leaching studies. Sci. Total Environ. 2012;420:300-312.

14. Ke P, Song K, Liu Z. Encapsulation of scorodite using crystalline polyferric sulfate precipitated from the $\mathrm{Fe}(\mathrm{II})-\mathrm{SO}_{4}{ }^{2-}-\mathrm{O}_{2}-\mathrm{H}_{2} \mathrm{O}$ system. Hydrometallurgy 2018;180:78-87.

15. Jia M, Zhao J, Qin C, et al. Experiment Study on Producing Inorganic Gel with Montmorillonite. Non-metallic Mines 2018;41(3):61-63.

16. Xiao L, Wang Y, Sun Z, et al. A Novel, Solvent-Free Mechanochemistry Approach for Gold Extraction from Anode Slime. ACS Sustain. Chem. Eng. 2019;7(13):11415-11425.

17. Bhattacharyya KG, Sen Gupta S. Adsorption of a few heavy metals on natural and modified kaolinite and montmorillonite: A review. Adv. Colloid Interface Sci. 2008;140(2):114-131.

18. Kang S, Qin L, Zhao Y, et al. Enhanced removal of methyl orange on exfoliated montmorillonite/chitosan gel in presence of methylene blue. Chemosphere 2020;238:124693.

19. Gu X, Evans LJ, Barabash SJ. Modeling the adsorption of Cd(II), $\mathrm{Cu}(\mathrm{II}), \mathrm{Ni}(\mathrm{II}), \mathrm{Pb}(\mathrm{II})$ and $\mathrm{Zn}$ (II) onto montmorillonite. Geochim. Cosmochim. Acta. 2010;74(20):5718-5728.

20. Yan H, Cui J, Zhang Z. Effects of interlayer cations on its gel performances of montmorillonite. China Power Sci. Technol. 2019;25(3):48-54.

21. Zou J, Pierre AC. Scanning electron-microscopy observations of card-house structures in montmorillonite gels. J. Mater. Sci. Lett. 1992;11(10):664-665.

22. Kang S, Zhao Y, Wang W, et al. Removal of methylene blue from water with montmorillonite nanosheets/chitosan hydrogels as adsorbent. Appl. Surf. Sci. 2018;448:203-211.

23. Wang $\mathrm{W}$, Zhao $\mathrm{Y}$, Yi $\mathrm{H}$, et al. Pb(IotaIota) removal from water using porous hydrogel of chitosan-2D montmorillonite. Int. J. Biol. Macromol. 2019;128:85-93.

24. Leetmaa K, Guo F, Becze L, et al. Stabilization of iron arsenate solids by encapsulation with aluminum hydroxyl gels. J. Chem. Technol. Biotechnol. 2016;91(2):408-415.

25. Muller K, Ciminelli VST, Dantas MSS, et al. A comparative study of $\mathrm{As}(\mathrm{III})$ and $\mathrm{As}(\mathrm{V})$ in aqueous solutions and adsorbed on iron oxy-hydroxides by Raman spectroscopy. Water Res. 2010;44(19):5660-5672.

26. Singh LP, Bhattacharyya SK, Shah SP, et al. Studies on early stage hydration of tricalcium silicate incorporating silica nanoparticles: Part I. Constr. Build. Mater. 2015;74:278-286.

27. Yu P, Kirkpatrick RJ, Poe B, et al. Structure of calcium silicate hydrate (C-S-H): Near-, mid-, and far-infrared spectroscopy. J. Am. Ceram. Soc. 1999;82(3):742-748.

28. Singh LP, Bhattacharyya SK, Shah SP, et al. Studies on early stage hydration of tricalcium silicate incorporating silica nanoparticles: Part II. Constr. Build. Mater. 2016;102:943-949.

29. Liang CL, Zhang ZY, Zhang HD, et al. Ordered macroporous molecularly imprinted polymers prepared by a surface imprinting method and their applications to the direct extraction of flavonoids from Gingko leaves. Food Chem. 2020;309:125680. 30. Pujala RK, Bohidar HB. Slow dynamics and equilibrium gelation 
in fractionated montmorillonite nanoplatelet dispersions. Colloid. Polym. Sci. 2019;297(7-8):1053-1065.

31. Zhang Q, Li X, Zhao Y, et al. Preparation and performance of nanocomposite hydrogels based on different clay. Appl. Clay Sci. 2009;46(4):346-350.

32. Gallucci E, Zhang X, Scrivener KL. Effect of temperature on the microstructure of calcium silicate hydrate (C-S-H). Cem. Concr. Res. 2013;53:185-195.

33. Yan S, An Q, Xia L, et al. As(V) removal from water using the La(III)- Montmorillonite hydrogel beads. React. Funct. Polym. 2020;147:104456.

34. Shokri E, Yegani R, Pourabbas B, et al. Evaluation of modified montmorillonite with di-cationic surfactants as efficient and environmentally friendly adsorbents for arsenic removal from contaminated water. Water Sci. Technol. 2018;18(2):460-472.

35. Cong XD, Kirkpatrick RJ. Effects of the temperature and relative-humidity on the structure of C-S-H gel. Cem. Concr. Res. 1995;25(6):1237-1245.

36. Lagno F, Rocha SD, Chryssoulis S, et al. Scorodite encapsulation by controlled deposition of aluminum phosphate coatings. J. Hazard. Mater. 2010;181(1-3):526-534.

37. Almasri DA, Rhadfi T, Atieh MA, et al. High performance hydroxyiron modified montmorillonite nanoclay adsorbent for arsenite removal. Chem. Eng. J. 2018;335:1-12.

38. Shokri E, Yegani R, Pourabbas B, et al. Evaluation of modified montmorillonite with di-cationic surfactants as efficient and environmentally friendly adsorbents for arsenic removal from contaminated water. Water Sci. Technol. Water Supply. 2018; 18(2):460-472.

39. Barakan S, Aghazadeh V, Beyragh AS, et al. Thermodynamic, kinetic and equilibrium isotherm studies of $\mathrm{As}(\mathrm{V})$ adsorption by Fe(III)-impregnated bentonite. Environ. Dev. Sustain. 2020;22(6):5273-5295.

40. Mukhopadhyay R, Manjaiah KM, Datta SC, et al. Inorganically modified clay minerals: Preparation, characterization, and arsenic adsorption in contaminated water and soil. Appl. Clay Sci. 2017;147:1-10. 